\title{
ANÁLISE DE VIBRAÇÕES DE PASSARELAS TUBULARES MISTAS (AÇO- CONCRETO) VIA MÉTODO DOS ELEMENTOS FINITOS
}

\author{
G. L. Debona ${ }^{1}$, J. G. S. da Silva ${ }^{2}$, A. C. C. Sieira ${ }^{2}$, P. C. G. da S. Vellasco ${ }^{2}$, L. R. O de Lima ${ }^{2}$ \\ ${ }^{1}$ Programa de Pós-graduação em Engenharia Civil, PGECIV, Universidade do Estado do Rio \\ de Janeiro, UERJ (gilvanld@yahoo.com.br)
}

${ }^{2}$ Departmento de Estruturas e Fundações, Universidade do Estado do Rio de Janeiro, UERJ

Resumo. Este trabalho de pesquisa apresenta como objetivo principal a investigação acerca do comportamento dinâmico de passarelas tubulares em aço e mistas (aço-concreto). Para tal, o sistema estrutural estudado corresponde a uma estrutura real, existente, sendo composta por três vãos (32,5m, 17,5m e 20,0m, respectivamente) e dois balanços (7,50m e 5,0m, respectivamente), apresentando um comprimento total de $82,5 \mathrm{~m}$. A passarela é composta por uma estrutura tubular de aço (treliças metálicas) e lajes de concreto, formando um sistema misto com interação completa. O modelo estrutural é submetido correntemente à travessia de pedestres e ciclistas. Testes experimentais foram realizados sobre o modelo estrutural e confrontados com resultados numéricos. Para a modelagem numérica do sistema são empregadas técnicas usuais de discretização, via método dos elementos finitos (MEF), por meio do programa ANSYS. Com base na metodologia de análise desenvolvida, a partir da obtenção dos resultados experimentais e numéricos, a resposta dinâmica da passarela, em termos das frequências naturais e acelerações de pico, é comparada com os valores limites propostos por normas e recomendações de projeto, objetivando uma avaliação do desempenho da estrutura, no que diz respeito ao problema de vibrações oriundo do caminhar dos pedestres.

Palavras-chave: Passarelas de pedestres tubulares, Dinâmica estrutural, Conforto humano.

\section{INTRODUÇÃO}

Considerando-se um avanço tecnológico considerável alcançado nos últimos anos em diversos setores produtivos e, também, em diversas áreas de pesquisa associadas à engenharia civil, em consonância com o arrojo crescente dos projetos arquitetônicos, as passarelas de pedestres têm sido projetadas cada vez mais leves e esbeltas.

Este procedimento de projeto tem gerado sistemas estruturais com vãos livres significativos, portanto muito esbeltos e, consequentemente, alterando os estados limites últimos e de utilização que norteiam o dimensionamento deste tipo de sistema estrutural. Uma consequência imediata desta nova tendência de projeto diz respeito a um aumento considerável dos problemas associados à vibração excessiva deste tipo de sistema estrutural [1-7]. No caso par- 
ticular das passarelas de pedestres este fenômeno ocorre, especialmente, quando a frequência fundamental da estrutura é igual ou mesmo se aproxima da frequência do passo humano.

Considerando-se os aspectos mencionados anteriormente, este trabalho de pesquisa apresenta como objetivo principal a investigação acerca do comportamento dinâmico de passarelas tubulares em aço e mistas (aço-concreto). Para tal, o sistema estrutural estudado corresponde a uma estrutura real, existente, localizada sobre as avenidas Osvaldo Aranha e Maracanã em São Cristóvão, na cidade do Rio de Janeiro/RJ, Brasil. A passarela de pedestres é composta por três vãos $(32,5 \mathrm{~m}, 17,5 \mathrm{~m}$ e $20,0 \mathrm{~m}$, respectivamente) e dois balanços $(7,50 \mathrm{~m}$ e $5,0 \mathrm{~m}$, respectivamente), apresentando um comprimento total de $82,5 \mathrm{~m}$.

O modelo estrutural investigado é composto por uma estrutura tubular de aço (treliças metálicas) e lajes de concreto, formando um sistema misto com interação completa. O modelo estrutural é submetido correntemente à travessia de pedestres e ciclistas. Testes experimentais foram realizados sobre o modelo estrutural [7] e confrontados com resultados numéricos [2].

Para a modelagem numérica do sistema são empregadas técnicas usuais de discretização, via método dos elementos finitos (MEF), por meio do programa ANSYS [8]. Com base na metodologia de análise desenvolvida, e considerando-se a obtenção e avaliação dos resultados experimentais e numéricos, a resposta dinâmica da passarela (frequências naturais e acelerações de pico) é avaliada mediante uma comparação com os valores limites propostos por normas e recomendações de projeto [6,9], objetivando uma avaliação mais racional e realista sobre o desempenho da estrutura, no que diz respeito ao problema de vibrações oriundo do caminhar dos pedestres.

Finalmente, com base nos resultados alcançados ao longo deste trabalho de pesquisa, pretende-se alertar os projetistas desse tipo de estrutura para os valores elevados de acelerações encontrados, o que pode representar um forte indício de que os critérios de projeto utilizados atualmente merecem ser revistos.

\section{MODELAGEM DA AÇÃO HUMANA}

Cargas de natureza dinâmica podem produzir elevados níveis de vibração que podem vir a comprometer a segurança estrutural como também causar alteração na sensação de conforto dos ocupantes dessas edificações. Vibrações induzidas pelo caminhar humano têm sido consideradas na análise dinâmica de passarelas de pedestres, de forma cada vez mais elaborada. De modo geral, a comunidade cientifica tem ciência de que o processo referente à modelagem das cargas dinâmicas induzidas por seres humanos é bastante complexo.

As características representativas das cargas geradas durante a execução destas atividades humanas são de difícil definição encontram-se associadas às particularidades corporais de cada indivíduo e a maneira como realizam um determinado tipo de ação. Tais características peculiares podem incluir idade, peso, sexo, tipo de calçado, etc. Isto pode ser notado no caso específico da locomoção, onde cada indivíduo tende a assumir um tipo de marcha e de velocidade mais eficiente de acordo com a sua estrutura particular.

Na tentativa de modelagem do carregamento dinâmico, inúmeros modelos são estudados, objetivando representar a ação dinâmica gerada durante o caminhar de pessoas para uma avaliação mais realista acerca da resposta dinâmica de passarelas de pedestres. 


\subsection{Modelo Proposto por Bachmann [1]}

A função representativa do caminhar humano é representada por uma série de Fourier. O modelo de carregamento considera que todos os pedestres, ao caminhar, produzem exatamente a mesma força na passada e que esta força é periódica. Para uma pessoa, a força repetitiva pode ser representada por uma combinação de forças senoidais, cujas frequências são múltiplos ou harmônicos da frequência básica da força repetitiva do passo, $\mathrm{f}_{\mathrm{p}}$, associada às atividades humanas. Este carregamento é produzido pelos dois pés, como uma função da parcela estática associada com o peso do individuo. Esses harmônicos surgem devido à interação entre a carga crescente representada por um pé e pelo simultâneo descarregamento referente ao outro pé. A representação matemática da ação dinâmica vertical induzida pelo caminhar humano é dada pela Equação (1).

$$
F(t)=P\left[1+\sum \alpha_{i} \cos \left(2 \pi i f_{p} t+\phi_{i}\right)\right]
$$

Onde:

$\mathrm{F}(\mathrm{t}) \quad$ : função de carregamento dinâmico;

$\mathrm{P} \quad$ : peso de uma pessoa $(700 \mathrm{~N})$;

$\alpha_{i} \quad$ : coeficiente dinâmico para a força harmônica (fator de carga dinâmica);

i : : múltiplo do harmônico (1, 2, 3, etc.);

$\mathrm{f}_{\mathrm{p}} \quad$ : frequência do passo humano;

$\phi_{\mathrm{i}} \quad$ : ângulo de fase para o harmônico i;

t : tempo.

A formulação proposta por Bachmann [1] considera cinco harmônicos na composição da ação dinâmica representativa da caminhada humana e os coeficientes dinâmicos associados a estes harmônicos estão expressos na Tabela 1.

Tabela 1. Coeficientes dinâmicos [1].

\begin{tabular}{ccc}
\hline Harmônico i & Coeficiente Dinâmico $\left(\alpha_{\mathrm{i}}\right)$ & Ângulo de Fase $\left(\phi_{\mathrm{i}}\right)$ \\
\hline 1 & 0,37 & 0 \\
2 & 0,10 & $\pi / 2$ \\
3 & 0,12 & $\pi / 2$ \\
4 & 0,04 & $\pi / 2$ \\
5 & 0,08 & $\pi / 2$ \\
\hline
\end{tabular}

Na sequência do trabalho, a Figura 1 apresenta uma função de carregamento dinâmico vertical, a qual representa um pedestre caminhando sobre a estrutura.

\subsection{Modelo Proposto pelo AISC [6]}

O modelo de função proposta pelo AISC [6] se baseia na mesma formulação do Bachmann [1], representando a caminhada humana em uma série de Fourier, conforme Equação (1). 
A formulação proposta pelo AISC [6] considera quatro harmônicos na composição da ação dinâmica representativa da caminhada humana e os coeficientes dinâmicos transversal vertical associados a estes harmônicos estão expressos na Tabela 2.

Tabela 2. Coeficientes dinâmicos [6].

\begin{tabular}{ccc}
\hline Harmônico i & Coeficiente Dinâmico $\left(\alpha_{\mathrm{i}}\right)$ & Ângulo de Fase $\left(\phi_{\mathrm{i}}\right)$ \\
\hline 1 & 0,50 & 0 \\
2 & 0,20 & $\pi / 2$ \\
3 & 0,10 & $\pi$ \\
4 & 0,05 & $3 \pi / 2$ \\
\hline
\end{tabular}

A Figura 2 apresenta a função de carregamento dinâmico vertical, a qual representa um pedestre caminhando sobre a estrutura, de acordo com o modelo proposto pelo AISC [6].

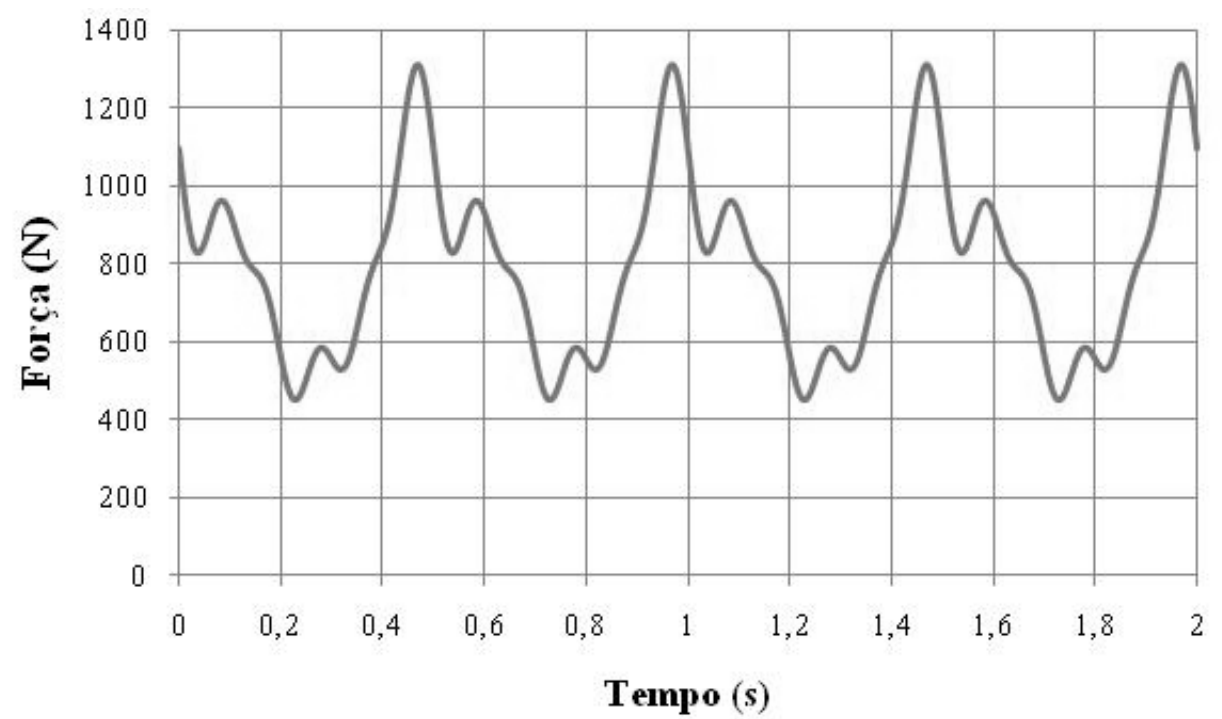

Figura 1. Função de carregamento dinâmico para uma pessoa caminhando com $\mathrm{f}_{\mathrm{p}}=2 \mathrm{~Hz}$.

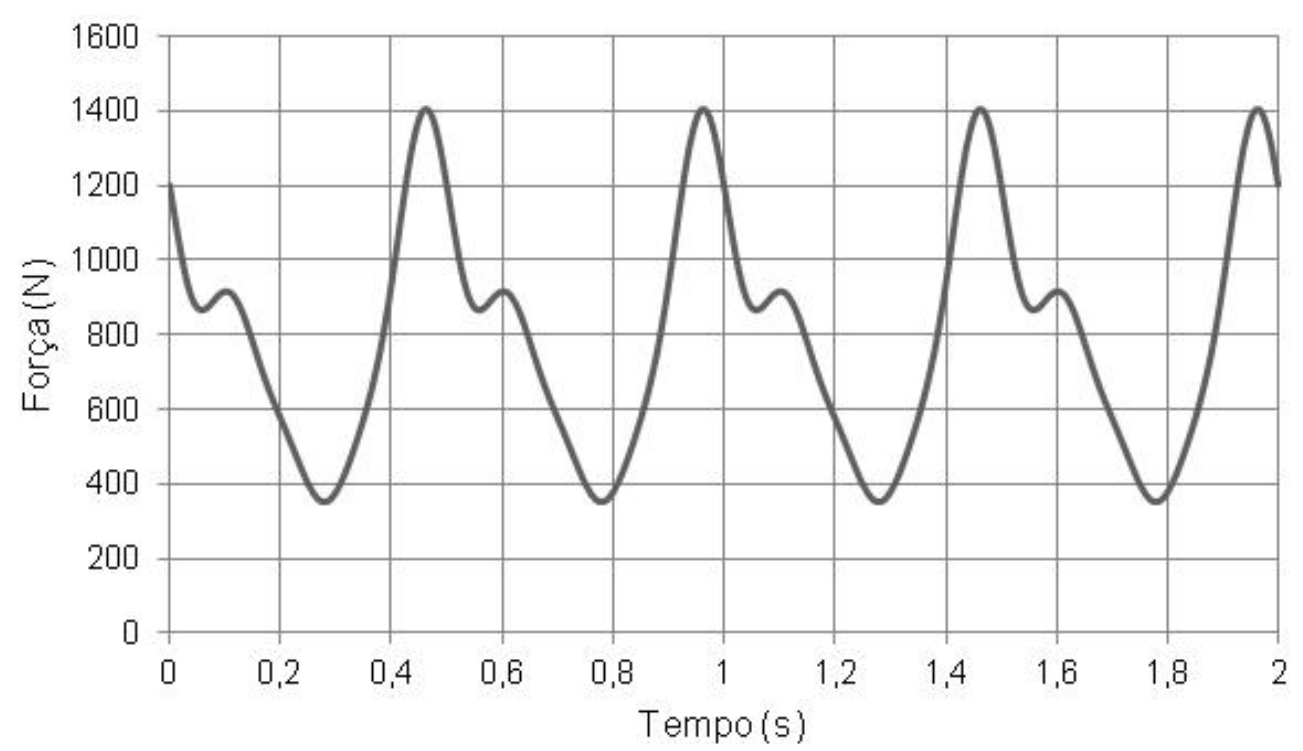

Figura 2. Função de carregamento dinâmico para uma pessoa caminhando com $\mathrm{f}_{\mathrm{p}}=2 \mathrm{~Hz}$. 


\subsection{Modelo proposto pelo CEB (Comité Euro-International du Béton) [10]}

O CEB [10] propõe um modelo determinístico no domínio do tempo para representar os carregamentos provocados por ações humanas. O modelo proposto pelo CEB [10] para a função de carregamento dinâmico vertical do movimento de caminhar é uma função periódica representada por uma série de Fourier, de acordo com a Equação (2).

$$
\begin{aligned}
& F(t)=P_{0}+\sum \Delta_{i} P_{0} \operatorname{sen}\left(2 i \pi f_{p} t-\phi_{i}\right)= \\
& =P_{0}+\Delta_{1} P_{0} \operatorname{sen}\left(2 \pi f_{p} t\right)+\Delta_{2} P_{0} \operatorname{sen}\left(4 \pi f_{p} t-\phi_{2}\right)
\end{aligned}
$$

Onde:

$\Delta_{\mathrm{i}} \mathrm{P}_{0}$ : Amplitude da Força do Harmônico.

A formulação proposta pelo CEB [10] considera apenas três harmônicos na composição da ação dinâmica representativa do caminhar e os coeficientes dinâmicos associados a estes harmônicos estão expressos na Tabela 3.

Tabela 3. Coeficientes dinâmicos [10].

\begin{tabular}{ccc}
\hline Harmônico i & Coeficiente Dinâmico $\left(\alpha_{\mathrm{i}}\right)$ & Angulo de Fase $\left(\phi_{\mathrm{i}}\right)$ \\
\hline 1 & 0,40 & 0 \\
2 & 0,10 & $\pi / 2$ \\
3 & 0,10 & $\pi / 2$ \\
\hline
\end{tabular}

Na sequência do trabalho, a Figura 3 apresenta uma função de carregamento dinâmico vertical, a qual representa um pedestre caminhando sobre a estrutura.

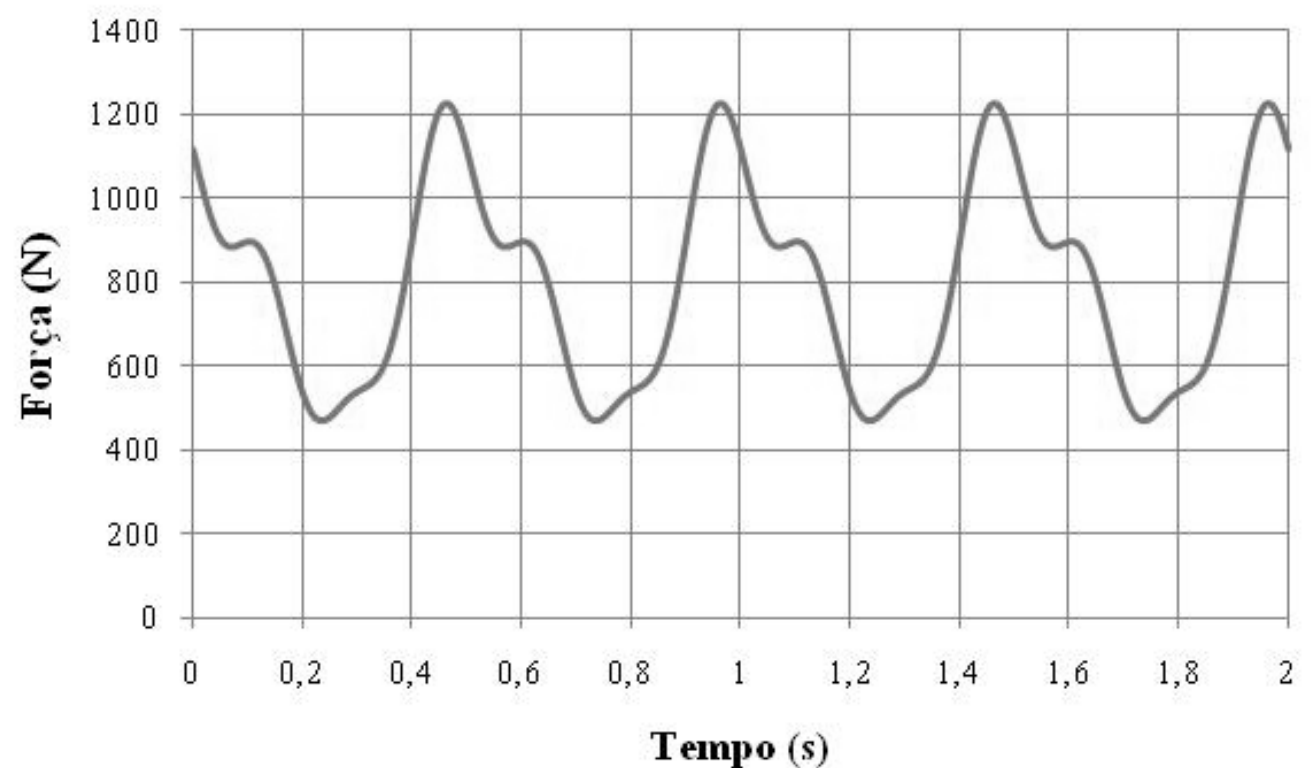

Figura 3. Função de carregamento dinâmico para uma pessoa caminhando com $\mathrm{f}_{\mathrm{p}}=2 \mathrm{~Hz}$. 


\subsection{Modelo proposto por Varela [11]}

Este modelo matemático baseia-se em uma análise mais realista para representar a excitação dinâmica proveniente do pedestre, de forma a incorporar o impacto transiente do calcanhar humano devido ao caminhar. O modelo adotado no presente estudo foi proposto a partir de uma aproximação matemática respaldada por estudos experimentais que permitiram registrar a reação total de um piso, gerada ao longo do tempo, durante uma caminhada sobre plataformas rígidas [11-12].

Assim sendo, a carga dinâmica associada ao caminhar humano, considerando-se a incorporação do efeito do impacto do calcanhar, é obtida a partir das Equações (3) a (6) [11]. A função matemática proposta, utilizada para representar a carga dinâmica produzida por uma pessoa caminhando sobre um piso, não é simulada simplesmente por uma série de Fourier, pois a equação também incorpora em sua formulação o pico transiente representativo do impacto do calcanhar sobre o piso.

$$
F(t)= \begin{cases}\left(\frac{f_{m i} F_{m}-P}{0,04 T_{p}}\right) t+P & \text { se } 0 \leq t<0,04 T_{p} \\ f_{m i} F_{m}\left[\frac{C_{1}\left(t-0,04 T_{p}\right)}{0,02 T_{p}}+1\right] & \text { se } 0,04 T_{p} \leq t<0,06 T_{p} \\ F_{m} & \text { se } 0,06 T_{p} \leq t<0,15 T_{p} \\ P+\sum_{i=1}^{n h} P \alpha \operatorname{sen}\left[2 \pi i f_{p}\left(t+0,1 T_{p}\right)+\phi_{i}\right] & \text { se } 0,15 T_{p} \leq t<0,90 T_{p} \\ 10\left(P-C_{2}\right) \cdot\left(\frac{t}{T_{p}}-1\right)+P \quad \text { se } 0,90 T_{p} \leq t<T_{p}\end{cases}
$$

Onde:

$\mathrm{F}_{\mathrm{m}}$ :valor máximo da série de Fourier, dado pela Equação 4;

$f_{m i}$ : fator de majoração do impacto do calcanhar, $\left(f_{m i}=1,12\right),[11]$; 
$\mathrm{T}_{\mathrm{p}}$ : período do passo;

$\mathrm{C}_{1}$ : coeficiente dado pela Equação (5);

$\mathrm{C}_{2}$ : coeficiente dado pela Equação (6).

Na presente investigação, são utilizadas as Equações (3) a (6) para obtenção da excitação dinâmica, proveniente dos seres humanos caminhando sobre os pisos e adota-se, ainda, para o fator de amplificação do impacto do calcanhar humano o valor de $1,12\left(f_{m i}=1,12\right)$ [11]. Todavia, faz-se necessário enfatizar que este valor de 1,12 varia de pessoa para pessoa fato que motiva que o referido coeficiente mereça um estudo mais aprofundado. Neste modelo de carregamento, os coeficientes dinâmicos associados aos quatros primeiros harmônicos da caminhada são fornecidos pelo guia de projeto do AISC [6], de acordo com a Tabela 4.

Tabela 4. Coeficientes dinâmicos [6].

\begin{tabular}{ccc}
\hline Harmônico i & Coeficiente Dinâmico $\left(\alpha_{\mathrm{i}}\right)$ & Ângulo de Fase $\left(\phi_{\mathrm{i}}\right)$ \\
\hline 1 & 0,50 & 0 \\
2 & 0,20 & $\pi / 2$ \\
3 & 0,10 & $\pi$ \\
4 & 0,05 & $3 \pi / 2$ \\
\hline
\end{tabular}

Na sequência do estudo, a Figura 4 apresenta uma função de carregamento dinâmico vertical, a qual representa um pedestre caminhando sobre a passarela.

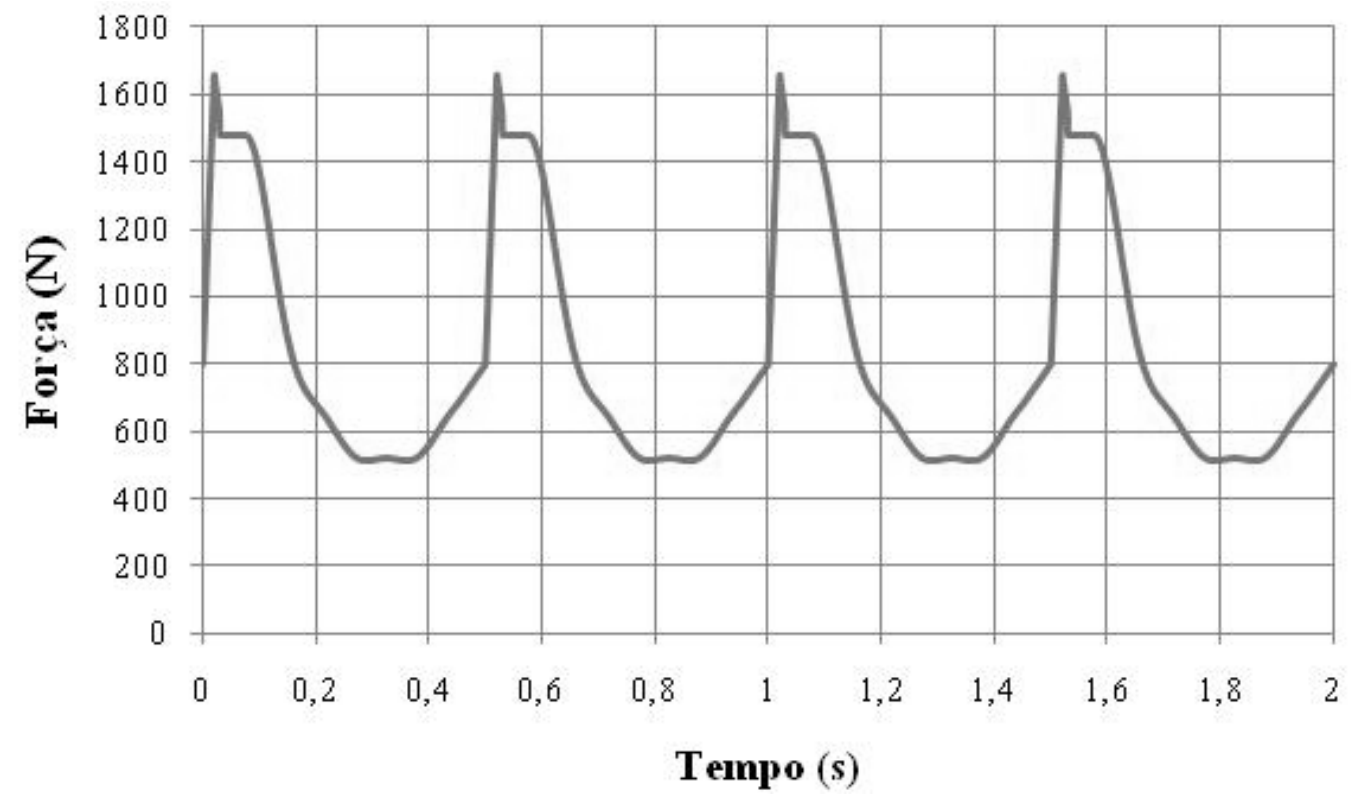

Figura 4. Função de carregamento dinâmico para uma pessoa caminhando com $\mathrm{f}_{\mathrm{p}}=2 \mathrm{~Hz}$.

\section{MODELO ESTRUTURAL INVESTIGADO}

O modelo estrutural investigado corresponde a uma estrutura real, existente, associada a uma passarela mista (aço-concreto) com 82,5 m de extensão, sendo composta por três vãos (32,5 m, 17,5 m e 20,0 m, respectivamente) e dois balanços (7,5 m e 5,0 m, respectivamente). 
A passarela é composta por uma estrutura tubular de aço (treliças metálicas) e lajes de concreto, formando um sistema misto com interação completa. O modelo estrutural é submetido correntemente à travessia de pedestres e ciclistas. $\mathrm{O}$ sistema estrutural está localizado sobre as avenidas Osvaldo Aranha e Maracanã em São Cristóvão na cidade do Rio de Janeiro/RJ, Brasil. A superestrutura da passarela possui todas as ligações soldadas. O sistema estrutural é constituído por duas treliças de aço planas que se interligam através de contraventamentos verticais fixados no perfil superior e inferior, em cada um dos nós que se formam no encontro com as diagonais, conforme ilustrado na Figura 5.

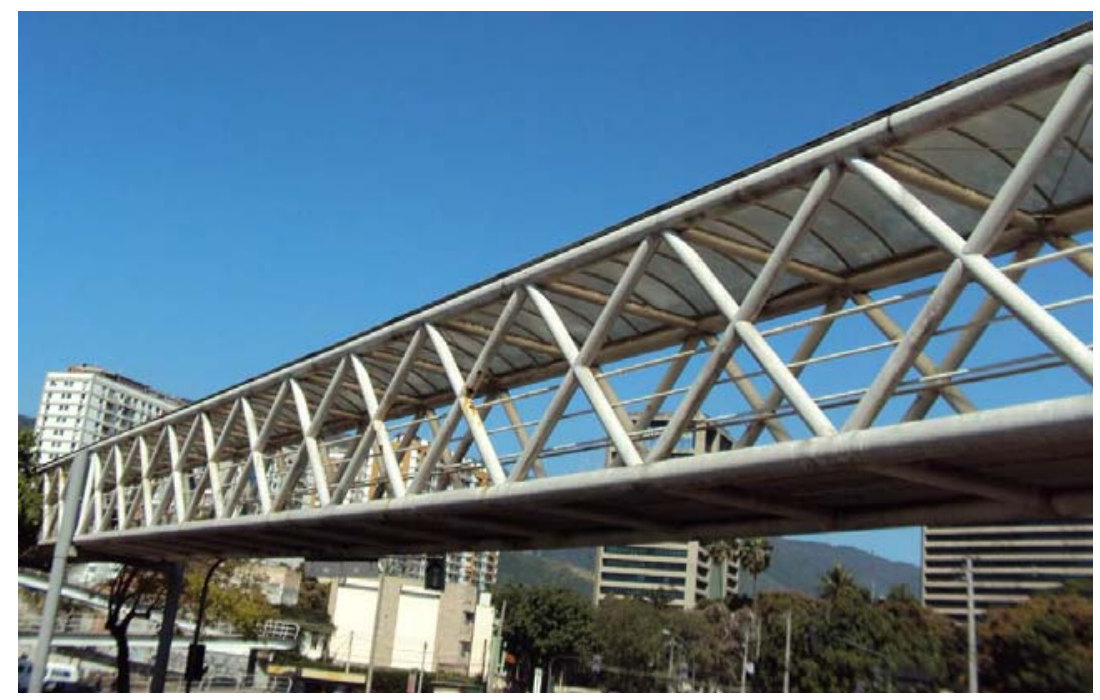

Figura 5. Vista lateral da passarela analisada.

A mesoestrutura da passarela é composta por quatro pórticos de aço formados por colunas tubulares ligadas a meia altura por vigas metálicas com perfis quadrados de $254 \mathrm{~mm} \mathrm{x}$ $254 \mathrm{~mm}$. Os dispositivos de apoio que estão fixados à viga travessa por solda recebem a superestrutura que se apoia pelo perfil longitudinal principal das treliças. Para garantir o funcionamento dos apoios, a interface entre estes é constituída por placas de neoprene.

As colunas, de altura efetiva variável, em função da topografia local, estão engastadas ao bloco de fundação através de chapas de base de $35 \mathrm{~mm}$ de espessura e parafusos, chumbados no concreto, com porca e contra porca. A fundação é composta, por estacas executadas por duplo trilho TR-37, soldados, com o comprimento estimado de $12 \mathrm{~m}$. O bloco de coroamento das estacas é de concreto armado de $0,65 \mathrm{~m}$ x $0,65 \mathrm{~m}$ e $1,20 \mathrm{~m}$ de altura com armadura de fretagem com estribos em forma de hélice. Entre os blocos de cada pórtico foi executada uma viga de equilíbrio de $0,40 \mathrm{~m} \times 0,70 \mathrm{~m}$.

O piso da passarela é constituído por placas de concreto pré-moldado que vencem o vão entre os contraventamentos (transversinas) inferiores. O rejuntamento entre as placas foi executado com argamassa, que pelas suas características, permite a percolação de água eventualmente acumulada. Complementa o sistema estrutural da passarela uma cobertura executada por laminados de policarbonato, estruturados em formato de arco para facilitar o escoamento de águas de chuva, o corrimão e guarda-corpo compostos por barras de seção tubular em aço. O sistema é constituído por uma série de elementos estruturais com diferentes características geométricas, de acordo com Zúñiga [7]. 
Com referência às características físicas do concreto, este possui uma resistência característica à compressão igual a $20 \mathrm{MPa}\left(\mathrm{f}_{\mathrm{ck}}=20 \mathrm{MPa}\right)$, módulo de elasticidade longitudinal igual a $2,13 \times 10^{10} \mathrm{~N} / \mathrm{m}^{2}\left(\mathrm{E}=2,13 \times 10^{10} \mathrm{~N} / \mathrm{m}^{2}\right)$, coeficiente de Poisson igual a $0,2(\mathrm{v}=0,2)$ e densidade de $2500 \mathrm{~kg} / \mathrm{m}^{3}\left(\rho=2500 \mathrm{~kg} / \mathrm{m}^{3}\right)$. No que diz respeito às características físicas do aço, este possui módulo de elasticidade longitudinal igual a $2,05 \times 10^{11} \mathrm{~N} / \mathrm{m}^{2}\left(\mathrm{E}=2,05 \times 10^{11}\right.$ $\left.\mathrm{N} / \mathrm{m}^{2}\right)$, coeficiente de Poisson igual a $0,3(\mathrm{v}=0,3)$ e densidade de $7850 \mathrm{~kg} / \mathrm{m}^{3}(\rho=7850$ $\left.\mathrm{kg} / \mathrm{m}^{3}\right)$.

\section{MONITORAÇÃO EXPERIMENTAL DINÂMICA}

A análise experimental da passarela foi feita mediante monitoração dinâmica, "in loco", por meio da instalação de acelerômetros na estrutura [7]. Foram realizados testes de vibração livre e forçada, com o objetivo de obter as frequências naturais do modelo, as funções de tempo associadas às acelerações em determinadas seções da passarela, e, ainda, o coeficiente de amortecimento estrutural. Para os ensaios associados à vibração forçada da estrutura, estes foram realizados com pessoas de porte médio, simulando o caminhar humano em velocidade do passo lenta, normal e rápida, com uma, duas e três pessoas, respectivamente, ao longo do vão da passarela. As frequências naturais de vibração da passarela de pedestres, obtidas via monitoração experimental dinâmica [7], encontram-se apresentadas na Tabela 5.

Tabela 5: Valores das frequências naturais obtidas experimentalmente [7].

\begin{tabular}{|c|c|c|}
\hline Modo de Vibração & Frequências Naturais $(\mathrm{Hz})$ & Características do Modo de Vibração \\
\hline $1^{0}$ & 1,56 & Modo de vibração longitudinal \\
\hline $2^{0}$ & 2,34 & Modo de vibração com flexão transversal \\
\hline $3^{0}$ & 5,08 & Modo de vibração com flexão vertical \\
\hline
\end{tabular}

\section{MODELO NUMÉRICO-COMPUTACIONAL}

No modelo numérico desenvolvido ao longo desta investigação são empregadas técnicas usuais de discretização, via método dos elementos finitos, por meio do emprego do programa ANSYS [8]. Neste modelo numérico, as vigas, colunas e transversinas são simulados por elementos finitos tridimensionais BEAM44 e PIPE16, onde são considerados os efeitos de flexão e de torção. A laje de concreto é simulada por meio de elementos finitos de casca SHELL63.

A ligação entre os aparelhos de apoio de neoprene e a estrutura metálica foi simulada com base no emprego de elementos finitos de mola não linear COMBIN39, conforme ilustrado na Figura 6. Considera-se, ainda, que o concreto trabalha no regime linear-elástico e que em ambos os elementos finitos as seções permanecem planas no estado deformado. São utilizadas, também, conexões rígidas do tipo "off-set", de forma a se garantir a compatibilidade de deformações entre os nós dos elementos de casca e nós dos elementos de viga tridimensionais. 


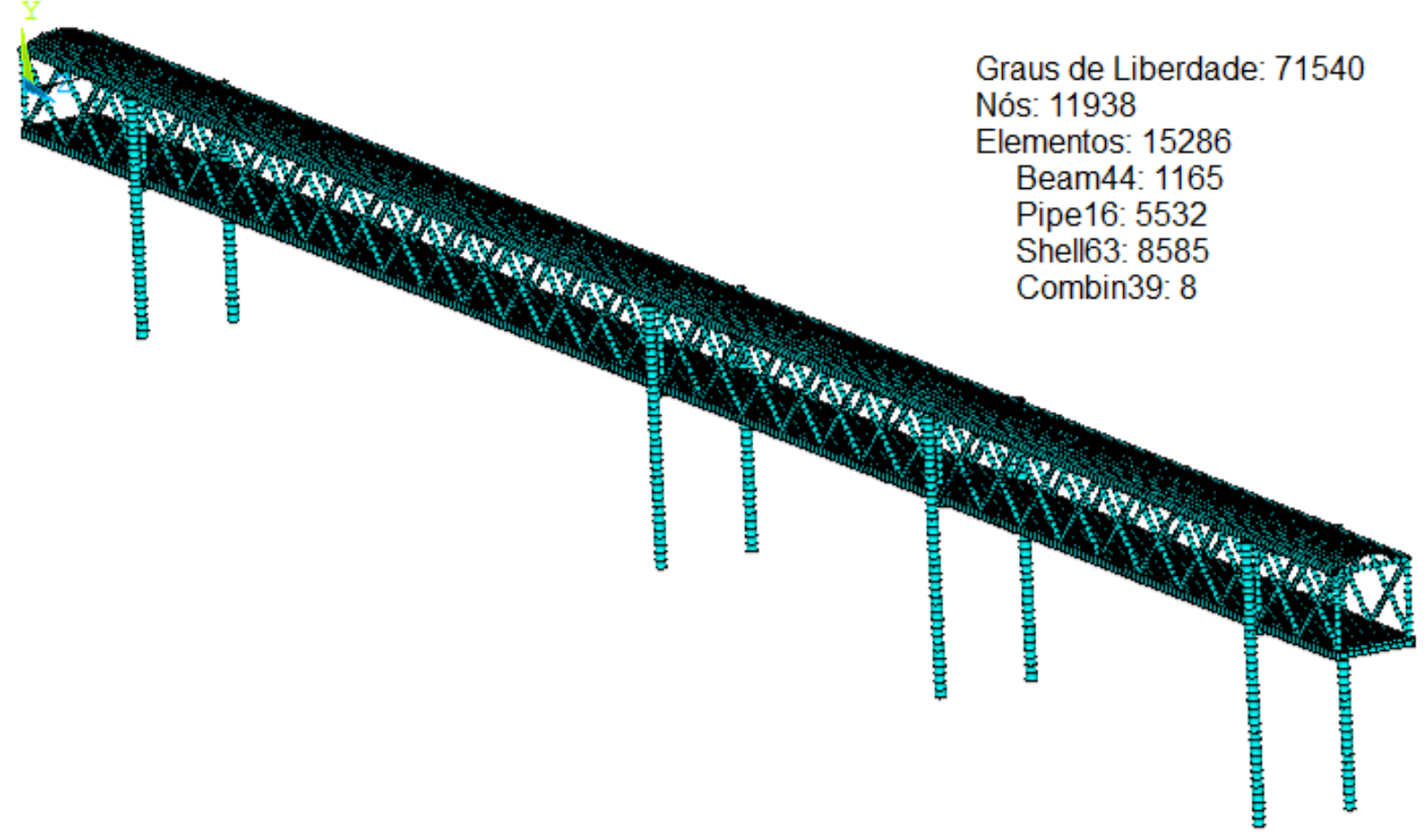

Figure 6. Modelo em elemento finitos desenvolvido para análise dinâmica da passarela.

\section{ANÁLISE DINÂMICA DA ESTRUTURA}

A resposta dinâmica da passarela tubular mista (aço-concreto) é determinada mediante a obtenção das frequências naturais, deslocamentos e acelerações máximas (acelerações de pico). Os resultados são obtidos através de uma análise numérica, com base no método dos elementos finitos, utilizando o programa ANSYS [8]. Ressalta-se que as acelerações verticais máximas da passarela são calculadas e comparadas com os limites propostos por normas e recomendações de projeto [6,9]. Tal comparação é feita objetivando verificar a ocorrência de níveis de vibrações indesejáveis e desconforto humano na estrutura.

\subsection{Análise das frequências naturais e dos modos de vibração da passarela}

Com base nas simulações numéricas realizadas ao longo do estudo, são determinadas as frequências naturais da passarela, como mostrado na Tabela 6. Em seguida, as Figuras 7 a 12 ilustram os modos de vibração correspondentes às seis primeiras frequências naturais do modelo estrutural.

Tabela 6: Frequências naturais da passarela.

\begin{tabular}{ccccccc}
\hline \multicolumn{7}{c}{ Frequências Naturais da Passarela (Hz) } \\
\hline Modelos & $\mathrm{f}_{01}$ & $\mathrm{f}_{02}$ & $\mathrm{f}_{03}$ & $\mathrm{f}_{04}$ & $\mathrm{f}_{05}$ & $\mathrm{f}_{06}$ \\
Numérico & 1,61 & 2,12 & 2,35 & 3,18 & 4,51 & 5,39 \\
Experimental & 1,56 & 2,34 & - & - & - & 5,08 \\
Erro (\%) & 3,2 & 9,4 & - & - & - & 6,10 \\
\hline
\end{tabular}


Comparando-se os valores das frequências naturais da passarela pode-se perceber que o modelo estrutural em estudo encontra-se bem representado numericamente pelo modelo computacional desenvolvido, via método dos elementos finitos (ANSYS [6]). As características dinâmicas do sistema, no que diz respeito às frequências naturais (massa e rigidez) estão bem representadas, pois o erro existente entre os valores numéricos e experimentais são muito pequenos, conforme ilustrado na Tabela 6 .

De acordo com as Figuras 7 a 12, percebe-se que o primeiro modo de vibração apresenta predominância de deslocamentos na direção longitudinal da estrutura. O segundo e quinto modos de vibração apresentam predominância de deslocamentos laterais associados a efeitos de torção. O terceiro e quarto modos de vibração do modelo apresentam predominância apenas de deslocamentos laterais. Estes cinco primeiros modos caracterizam-se por serem modos de vibração longitudinais e laterais da passarela, respectivamente, indicando que esta deve ser verificada, também, no que tange a ação de cargas dinâmicas horizontais. Finalmente, o sexto modo de vibração é marcado pela influência dos efeitos de flexão do maior vão da estrutura.

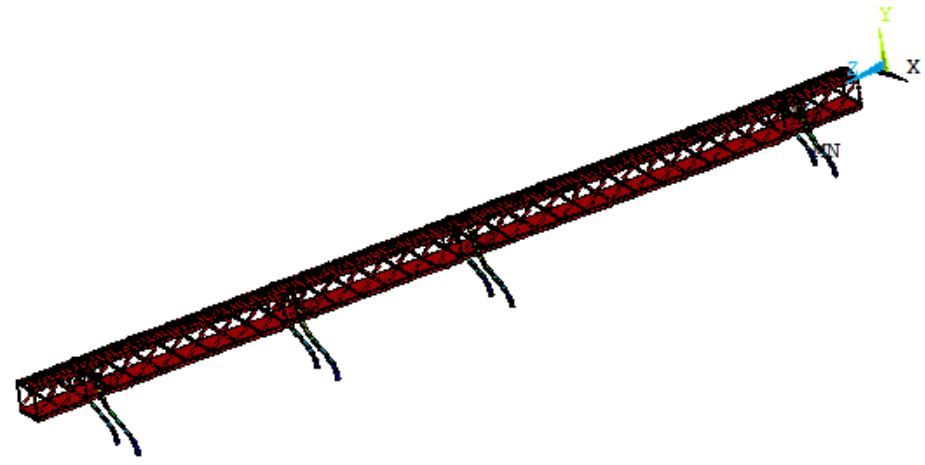

Figure 7. Modo de vibração referente à primeira frequência natural $\mathrm{f}_{01}=1,61 \mathrm{~Hz}$.

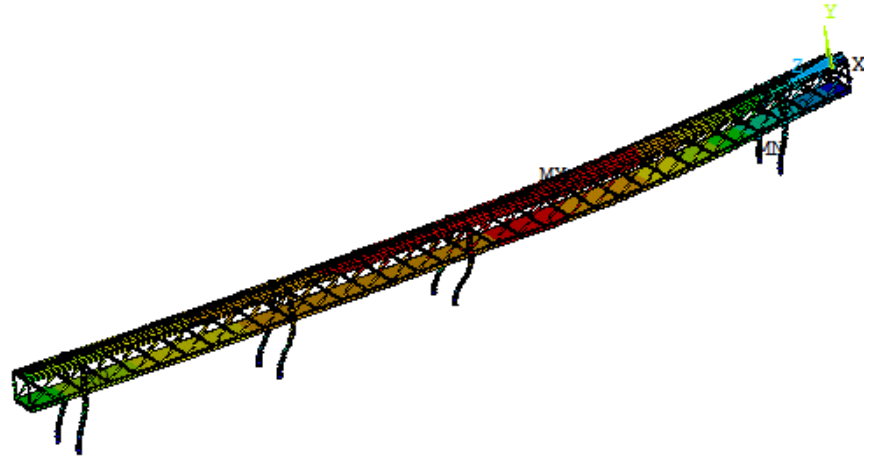

Figure 8. Modo de vibração referente à segunda frequência natural $\mathrm{f}_{02}=2,12 \mathrm{~Hz}$.

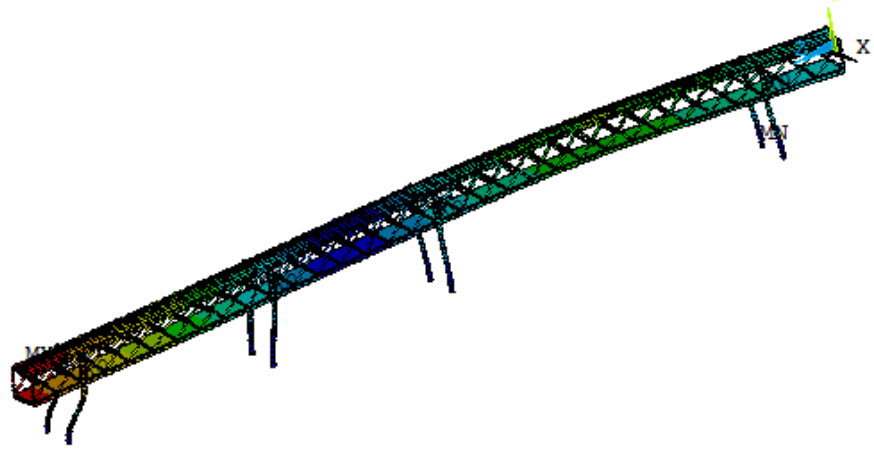

Figure 9. Modo de vibração referente à terceira frequência natural $\mathrm{f}_{03}=2,35 \mathrm{~Hz}$. 


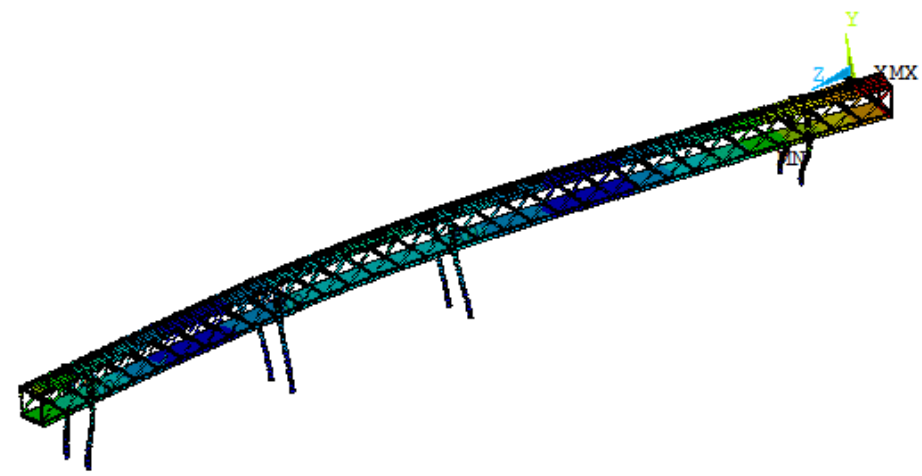

Figure 10. Modo de vibração referente à quarta frequência natural $\mathrm{f}_{04}=3,18 \mathrm{~Hz}$.

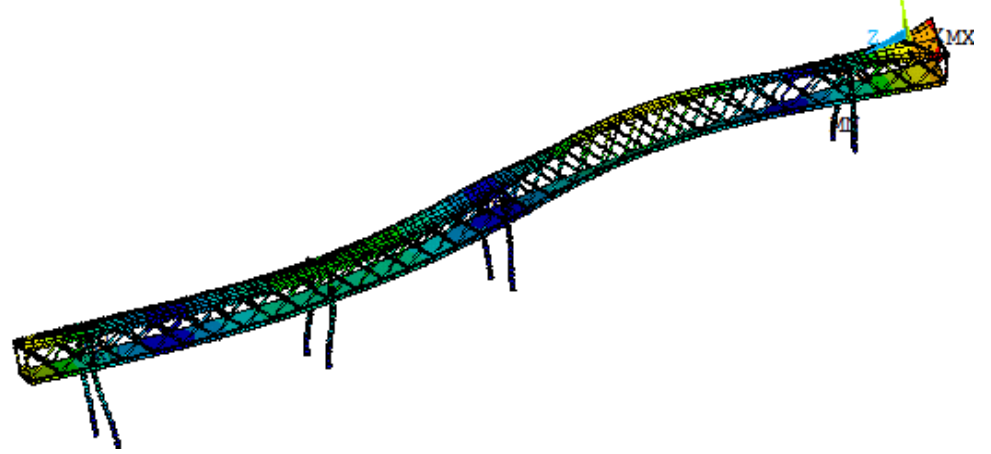

Figure 11. Modo de vibração referente à quinta frequência natural $\mathrm{f}_{05}=4,51 \mathrm{~Hz}$.

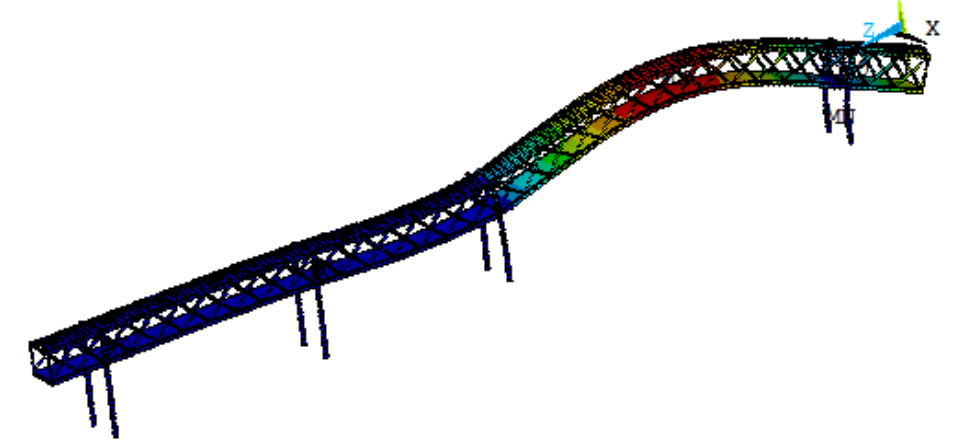

Figure 12. Modo de vibração referente à sexta frequência natural $\mathrm{f}_{06}=5,39 \mathrm{~Hz}$.

\subsection{Análise das acelerações máximas (acelerações de pico)}

Pretende-se verificar a adequabilidade da passarela quando submetida ao caminhar humano, no que tange ao desconforto relacionado a vibrações. Deste modo, os modelos de carregamento dinâmico descritos anteriormente foram aplicados como excitação dinâmica sobre a passarela em estudo, conforme a metodologia de análise descrita detalhadamente no trabalho de Debona [2], objetivando determinar as acelerações de pico.

Os valores das acelerações máximas são comparados com os valores limites propostos na literatura técnica $[6,9]$. Ressalta-se que foi considerado um coeficiente de amortecimento estrutural para o modelo igual a $1 \%(\xi=0,01)$, em consonância o valor do amortecimento estrutural medido experimentalmente [7]. Considera-se que o peso de uma pessoa é igual a 800 $\mathrm{N}$ [4]. Nesta investigação foram analisados os casos de carregamento associados à travessia de pedestres (uma, duas e três pessoas) cruzando a estrutura de lado a lado, em caminhada normal, conforme ilustrado nas Figuras 13 a 15. 


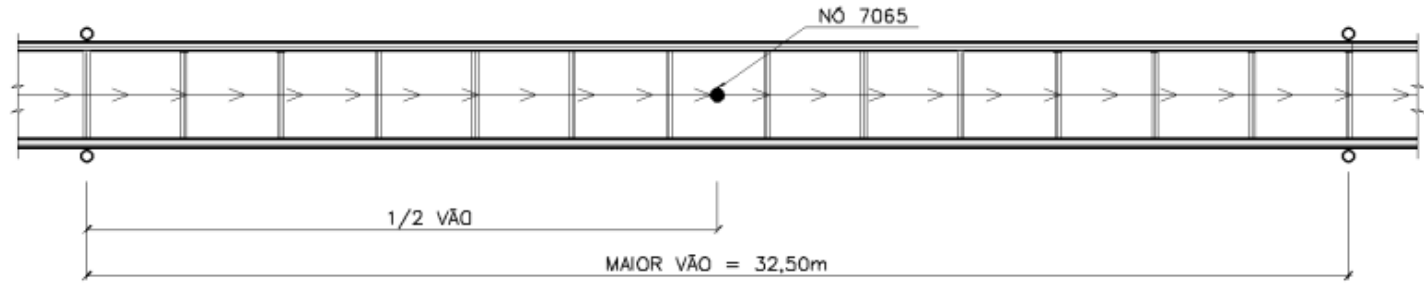

Figure 13. Caso de carregamento: uma pessoa caminhando.

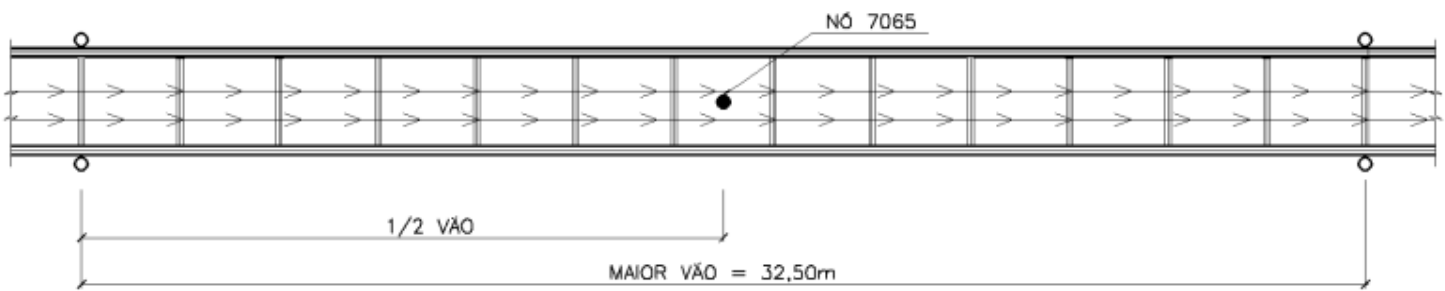

Figure 14. Caso de carregamento: duas pessoas caminhando.

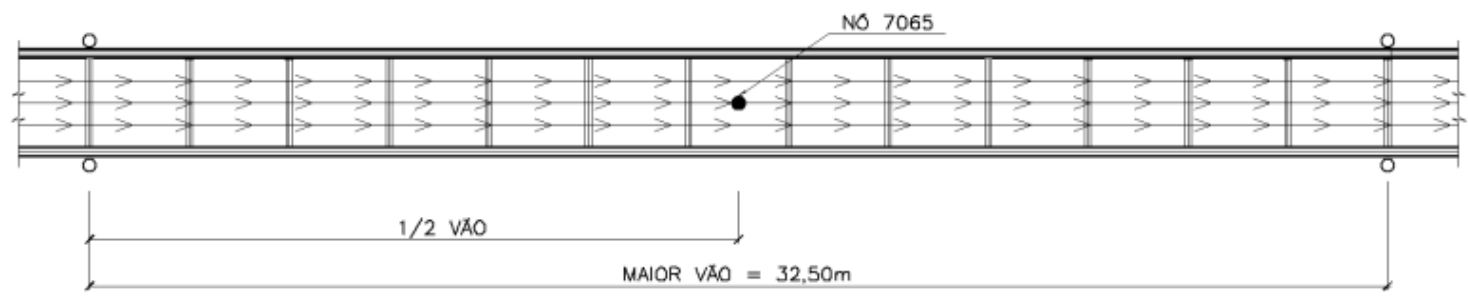

Figure 15. Caso de carregamento: três pessoas caminhando.

Na sequência do texto, as Figuras 16 a 19 ilustram a resposta dinâmica da passarela em estudo, quando submetida ao caminhar normal de um pedestre, em termos das acelerações máximas ao longo do tempo, no que diz respeito aos quatros modelos de carregamentos dinâmicos investigados (Bachmann [1]; AISC [6]; CEB [10]; Varela [11]). O ponto da estrutura analisado corresponde à seção central do maior vão da passarela (Nó 7065, Figuras 13 a 15).

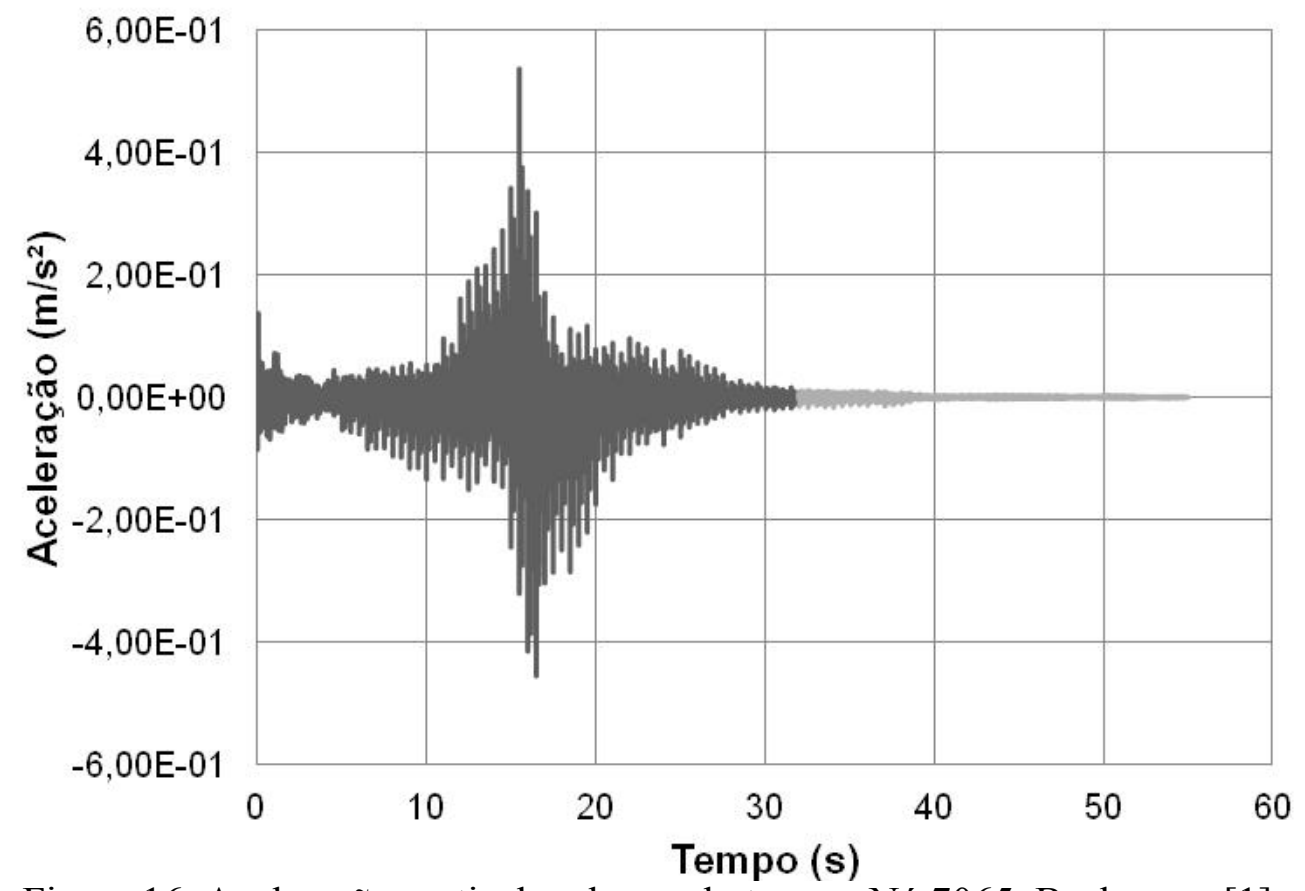

Figure 16. Aceleração vertical ao longo do tempo. Nó 7065. Bachmann [1]. 


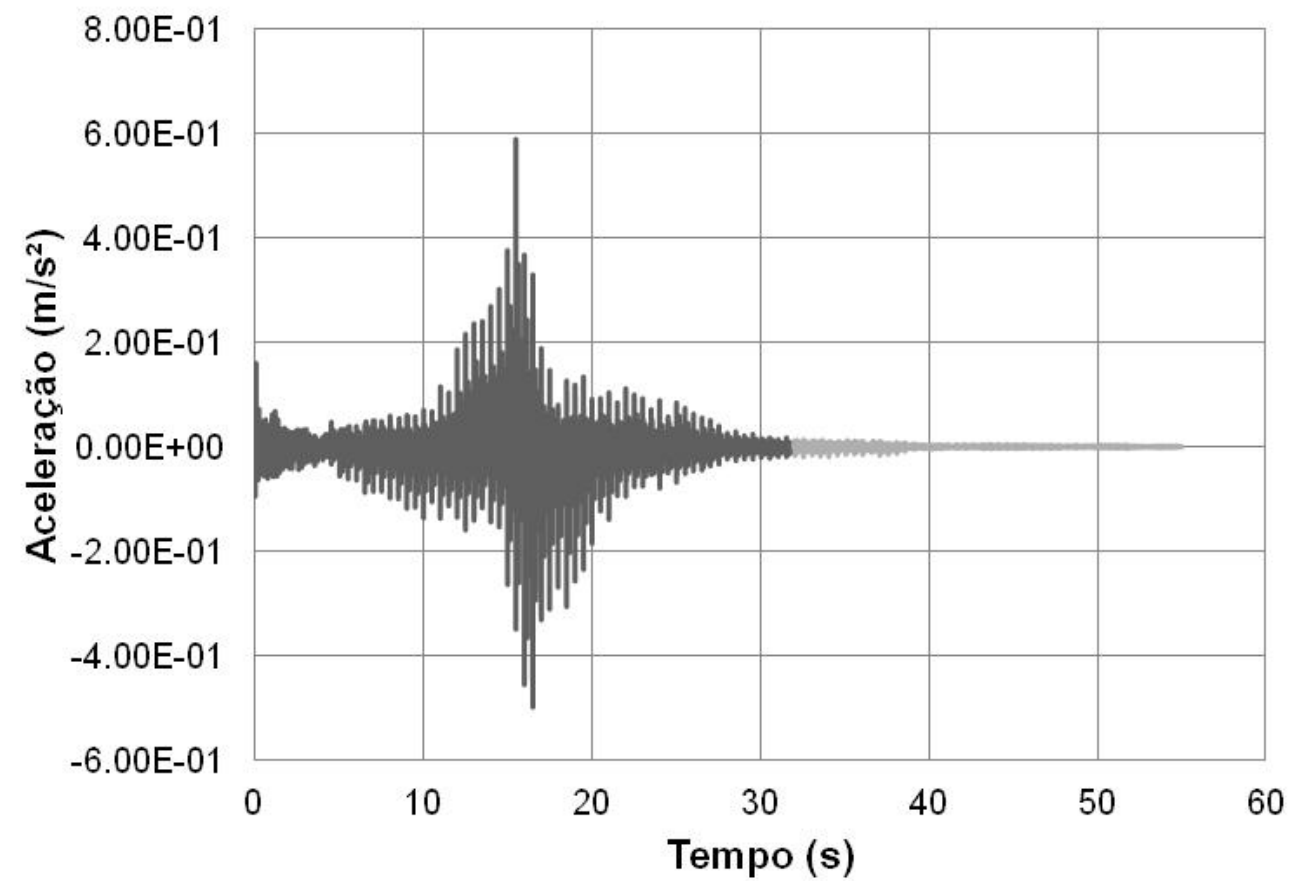

Figure 17. Aceleração vertical ao longo do tempo. Nó 7065. AISC [6].

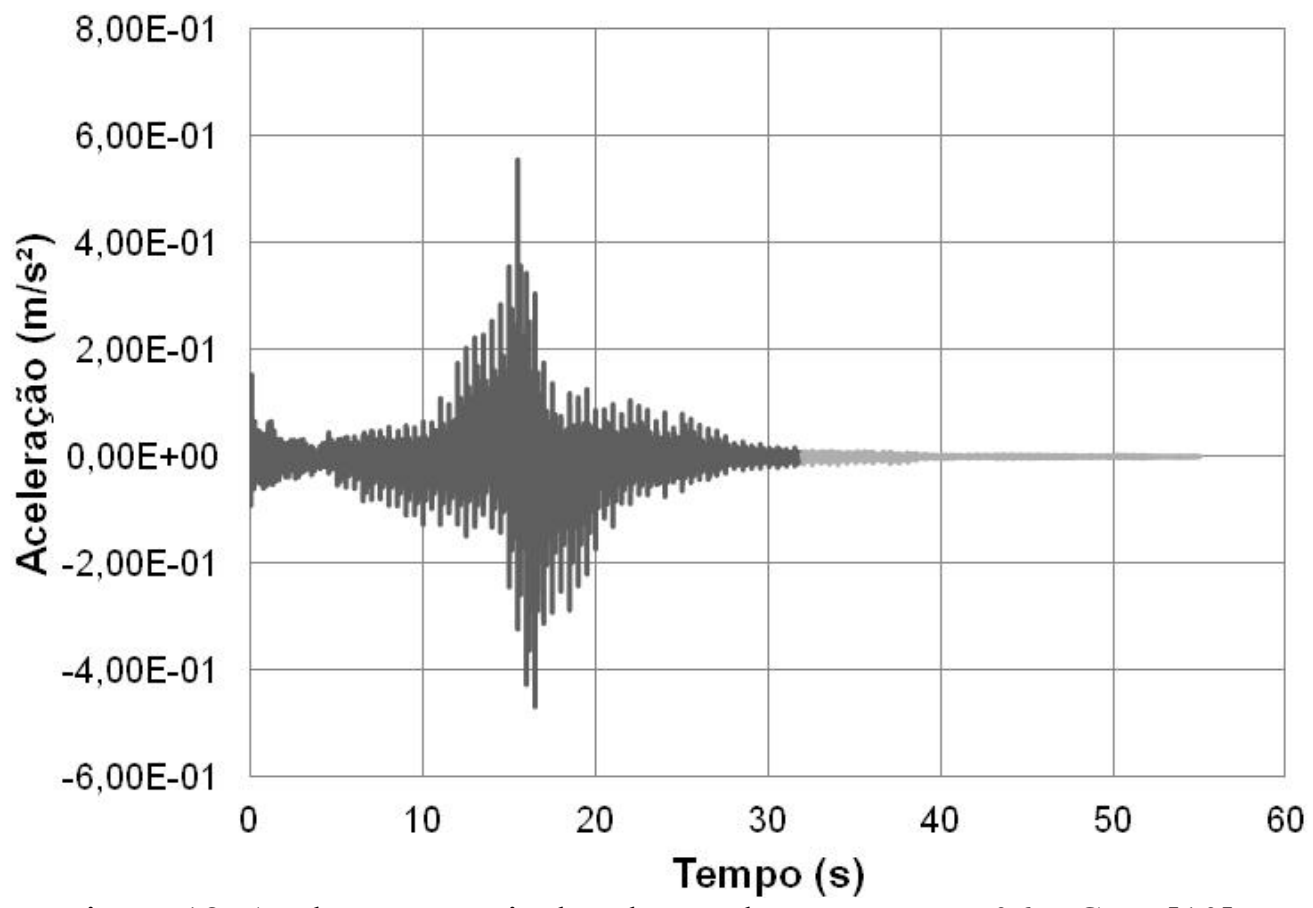

Figure 18. Aceleração vertical ao longo do tempo. Nó 7065. CEB [10]. 


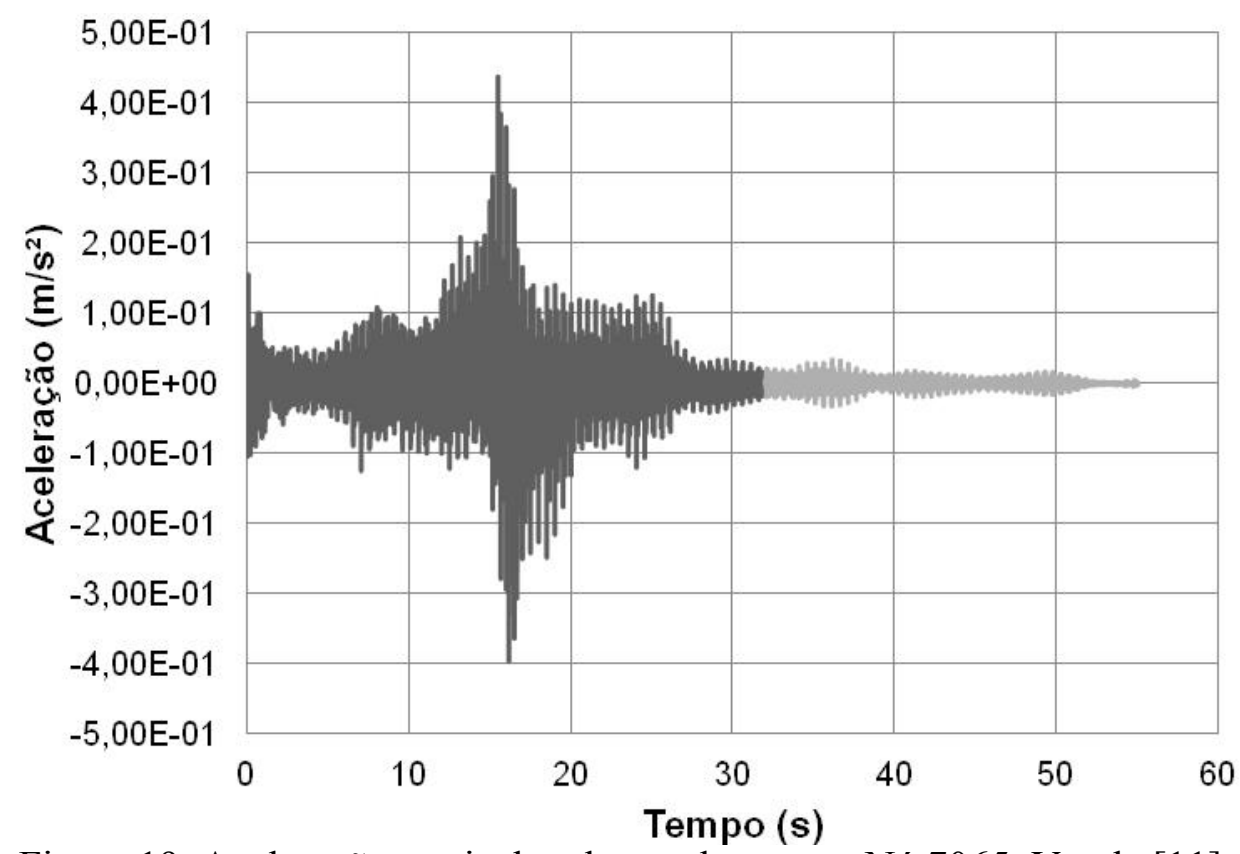

Figure 19. Aceleração vertical ao longo do tempo. Nó 7065. Varela [11].

Inicialmente, com base nas análises realizadas, pode-se concluir que os harmônicos componentes da excitação são bastante relevantes para a definição do carregamento dinâmico oriundo do pedestre, como também para a avaliação da resposta dinâmica das passarelas, principalmente quando estes harmônicos se encontram em ressonância com a estrutura.

No que diz respeito a uma análise quantitativa dos resultados obtidos, via métodos dos elementos finitos (análise numérica), foi verificado que o modelo de carregamento que gerou os maiores valores para as acelerações máximas (acelerações de pico) foi o modelo proposto pelo AISC [6] $\left(a_{p}=0,58 \mathrm{~m} / \mathrm{s}^{2}\right)$, Figura 17. Os demais modelos de carregamento empregados na análise resultaram em acelerações de pico da ordem de: $a_{p}=0,53 \mathrm{~m} / \mathrm{s}^{2}$ Bachmann [1] (Figura 16); $a_{p}=0,55 \mathrm{~m} / \mathrm{s}^{2}$ CEB [10] (Figura 18) e $a_{p}=0,45 \mathrm{~m} / \mathrm{s}^{2}$ Varela [11] (Figura 19).

De acordo com os resultados numéricos apresentados nas Figuras 16 a 19, verifica-se que, diante dos casos de carregamento considerados neste trabalho, a passarela investigada viola os critérios de conforto humano $\left(a_{p}=0,55 \mathrm{~m} / \mathrm{s}^{2}>a_{\lim }=0,49 \mathrm{~m} / \mathrm{s}^{2}[6,9]\right)$; quando uma ou mais pessoas caminham sobre a laje de concreto do modelo, exceção feita ao caso em que simula-se o caminhar de uma pessoa a partir do modelo proposto por Varela [11].

Os resultados obtidos reforçam a importância da consideração da ação dinâmica humana sobre passarelas de pedestres em aço e mistas (aço-concreto) e, bem como, apontam para a relevância de estudos mais detalhados acerca da modelagem da ação dinâmica proveniente dos pedestres.

\section{CONSIDERAÇÕES FINAIS}

A metodologia de análise desenvolvida considera o estudo do comportamento dinâmico linear em regime de serviço de passarelas. Este trabalho de pesquisa apresenta uma contribuição, no sentido de avaliar-se experimentalmente e numericamente o comportamento estrutural de passarelas de pedestres tubulares em aço e mistas, submetidas ao caminhar humano. 
O modelo estrutural utilizado baseia-se em uma passarela tubular mista (açoconcreto), correspondente a uma estrutura real, existente, localizada sobre as avenidas Osvaldo Aranha e Maracanã em São Cristóvão, na cidade do Rio de Janeiro/RJ, Brasil. A passarela de pedestres é composta por três vãos (32,5 m, 17,5 m e 20,0 m, respectivamente) e dois balanços (7,5 m e 5,0 m, respectivamente), apresentando um comprimento total de 82,5 m.

O modelo numérico-computacional foi desenvolvido com base no emprego de técnicas usuais do método dos elementos finitos, por meio da utilização do programa ANSYS [8]. O modelo numérico foi devidamente calibrado com resultados de testes experimentais realizados sobre a estrutura investigada. Desta forma, foi possível verificar e avaliar os níveis de vibração da estrutura, quando submetida ao caminhar dos pedestres.

A resposta dinâmica da passarela, em termos das acelerações de pico, foi obtida e comparada com os limites propostos por diversas normas e recomendações de projeto [6,9]. Foi constatado que o modelo estrutural analisado viola o limite de conforto humano $\left(a_{p}=0,55\right.$ $\left.\mathrm{m} / \mathrm{s}^{2}>\mathrm{a}_{\lim }=0,49 \mathrm{~m} / \mathrm{s}^{2}[6,9]\right)$, na maioria dos casos de carregamento investigados.

Os resultados encontrados ao longo desta investigação reforçam a urgência e relevância, no que diz respeito ao desenvolvimento de estudos mais detalhados acerca da modelagem da ação dinâmica proveniente dos pedestres sobre passarelas de pedestres em aço e mistas (aço-concreto).

\section{Agradecimentos}

Os autores agradecem ao suporte financeiro fornecido pelas Agências de Fomento à Pesquisa do país, CAPES, CNPq e FAPERJ, que possibilitaram a realização deste trabalho de pesquisa.

\section{REFERÊNCIAS}

[1] Bachmann, H. e Ammann, W. Vibrations in structures induced by man and machines, Structural Engineering Document 3e, International Association for Bridges and Structural Engineering, 1987.

[2] Debona, G.L. Modelagem do comportamento dinâmico de passarelas tubulares mistas (aço-concreto), submetidas ao caminhar humano, Dissertação de Mestrado, Programa de Pós-Graduação em Engenharia Civil, PGECIV, Universidade do Estado do Rio de Janeiro, UERJ, Rio de Janeiro, Brasil, 2011.

[3] Ellis, B.R. On the response of long-span floors to walking loads generated by individuals and crowds. The Structural Engineer, 78: 17-25, 2000.

[4] Figueiredo, F.P. Estudo do comportamento dinâmico de passarelas devido ao caminhar de pedestres, Dissertação de Mestrado, Programa de Pós-Graduação em Engenharia Civil, PGECIV, Universidade do Estado do Rio de Janeiro, UERJ, Rio de Janeiro, Brasil, 2005. 
[5] Lima, N.L. de A. Efeito da modelagem do carregamento, do impacto do calcanhar humano e do amortecimento estrutural na resposta dinâmica de passarelas mistas, Dissertação de Mestrado, Programa de Pós-Graduação em Engenharia Civil, PGECIV, Universidade do Estado do Rio de Janeiro, UERJ, Rio de Janeiro, Brasil, 2007.

[6] Murray, T.M., Allen, D.E., Ungar, E.E. Floor vibrations due to human activity, Steel Design Guide Series, American Institute of Steel Construction, AISC, Chicago, USA, 2003.

[7] Zúñiga, J. E. V. Análise da resposta dinâmica experimental de uma passarela tubular mista, aço-concreto, submetida ao caminhar humano, Dissertação de Mestrado, Programa de Pós-Graduação em Engenharia Civil, PGECIV, Universidade do Estado do Rio de Janeiro, UERJ, Rio de Janeiro, Brasil, 2011.

[8] ANSYS. Swanson Analysis Systems, Inc., P.O. Box 65, Johnson Road, Houston, PA, 15342-0065, Version 10.0, Basic analysis procedures, Second edition, 2009.

[9] International Standard Organization / ISO 2631-2. Evaluation of human exposure to whole-body vibration, Part 2: Human Exposure to Continuous and Shock-Induced Vibrations in Buildings ( 1 to $80 \mathrm{~Hz}$ ), International Standard, 1989.

[10] COMITÉ EURO-INTERNATIONAL DU BÉTON. CEB-FIP: Bulletin d'information, n. 209, England, London, aug. 1993.

[11] Varela, W.D. Modelo teórico-experimental para análises de vibrações induzidas por pessoas caminhando sobre lajes de edifícios, Tese de Doutorado, Universidade Federal do Rio de Janeiro, Departamento de Engenharia Civil, COPPE/UFRJ, Rio de Janeiro, Brasil, 2004.

[12] Ohlsson, S.V. Floor vibration and human disconfort, PhD Thesis, Department of Structural Engineering, Chalmers University of Technology, Gotemborg, Sweden, 1982. 